\title{
The Analysis of Three-dimensional Numerical Simulation to Complexity Foundation Pit Supporting System
}

\author{
YANG Tai-hua ${ }^{1, \text { a }, ~ S H A O ~ Z i-y a n g ~}{ }^{2}$, CHEN Yuan ${ }^{1, b}$ and HUANG Chuan-sheng ${ }^{3}$ \\ ${ }^{1}$ College of Urban Construct, Wuhan University of Science and Technology, Wuhan, China, 430070 \\ 2 Jiangsu China weft engineering design research co., LTD, Nanjing, China, 210019 \\ ${ }^{3}$ College of Civil Engineering and architecture, Central South University, Changsha, China, 410075 \\ ayangtaihua@wust.edu.cn, b641237930@qq.com
}

\begin{abstract}
Keywords: foundation pit; supporting system; three-dimensional; numerical simulation
Abstract: For the interchange foundation pit engineering of the Guangzhou No.3 and No.6 metro line, using three-dimensional elastic-plastic finite element method to build the overall modeling and to simulate the whole process of the excavation, and the calculation and analysis were made. The computation results show that: (1) the space effects of the foundation pit are very obvious. (2) Using the method to calculate the foundation pit, the calculating results and excavation site monitoring results are identical in the two perspectives of lateral deformation and strut axial forces. So using this calculation method to calculate the foundation pit is completely feasible. (3) calculated and analyzed the deformation of the foundation pit, some relevant advice were put forward, to expect to have a certain reference values for the advanced decision-making and hysteretic effect analysis of the project.
\end{abstract}

\section{Introduction}

Plane strain problem usually was used to simulate and calculate the supporting problem of deep foundation pit engineering, but strictly speaking, the deep foundation pit excavation and supporting belonged to a kind of three-dimensional problem. And now, three dimensional elastic-plastic finite element analysis considering contact were still not too many ${ }^{[1-5]}$, and there were more fewer to analyze the foundation pits whose sizes are super large and deep, and whose plane shapes are asymmetric. These may be related to the complexity of modeling, the difficulty of convergence, time-consuming of calculation and so on ${ }^{[6]}$. These required researchers build model more detailed, mesh quality be finer and control convergence criterion more accurately.

Here was the foundation pit engineering of Guangzhou metro transfer station between Line 3 and Line 6, it was simulated the whole excavation process by the 3D elastic-plastic finite element method, and the calculation results were made compared with the actual monitoring results on the deformation of supporting structure and axial force of the supports, so as to provide effective reference for the project advanced decision-making, lagged effect-analysis and information construction.

\section{General situation of engineering and the model introduce}

General situation of engineering. Yan-tang Station of Guangzhou City Rail Transit was a transfer station between Line 3 and Line 6, the foundation pit was 18 $32 \mathrm{~m}$ in depth, and was the deepest foundation pit in Guangzhou, its plane shape was cross-intersection, as

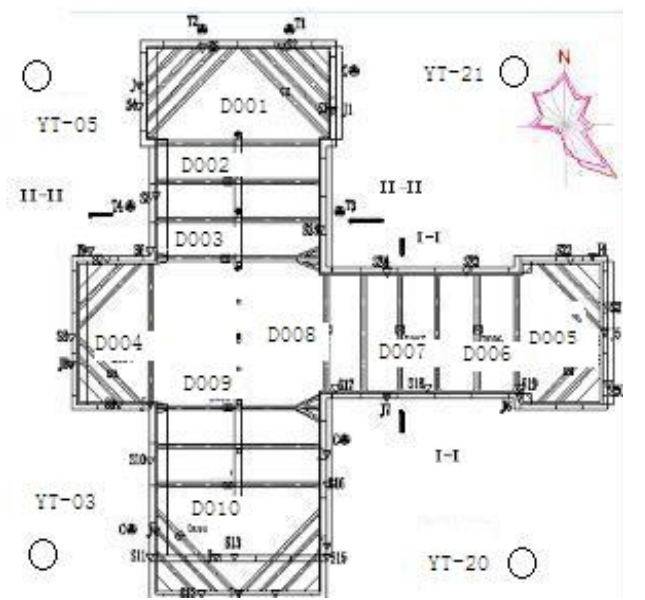

Fig.1 Layout plan of each monitoring point in the first foundation pit support plane shown in Fig.1, is an asymmetric structure. Considering the spatial effect of the foundation pit, we can only build the overall three-dimensional finite element model. The plane size of the project was 
relatively large: Line 3 was $86 \mathrm{~m}$ in length, and Line 6 was $85 \mathrm{~m}$. Considering the calculation difficulties of three-dimensional finite element, avoid producing abnormal elements and causing the calculation didn't converge finally because of the number of elements were too large. Under the premise of not affecting the calculation results, we must control strictly the model size, so the distance between the foundation pit edge and the model boundary was 2-3 times of the excavation depth ${ }^{[7]}$.

Model introduce of foundation pit.The depth of diaphragm walls of Line 3 and Line 6 were 35.5m and $17 \mathrm{~m}$ respectively. The thicknesses were $1 \mathrm{~m}$ and $0.8 \mathrm{~m}$, and were simulated by wall elements. The crown beams (or the waist beams) were reinforced concrete structure and supports were composite structure of reinforced concrete and steel tubes, they were modeled by beam elements. The meshing accuracy of the elements was fine, and the mesh of the soil in the foundation pit must be refined ${ }^{[8]}$. The soil layers were defined by the borehole function (i.e., drilling holes). The soil mass was simulated by soil element with 15 nodes. The constitutive model of soil was modeled by soil hardening model. Contact element was used in the interface between the diaphragm wall and the soil. The boundary condition of the model was that the laterals were restrained in horizontal direction, the bottom was fixed in all direction and the upper surface was free surface.

According to the geological investigation data, the distribution of every soil layer was approximately in the plane. In order to simplify the calculation, a drilling hole was taken at the four corners of the foundation pit, and the linear interpolation was adopted in the middle to form a spatial foundation soil layer. The parameters and distribution are listed in Table 1 and Table 2 as followed:

The excavation and supporting of foundation pit. During the excavation process, the excavating, supporting and loading of the foundation pit could all be achieved by activating and freezing a certain group of units. The initial stress of the foundation soil was applied by the means of $\mathrm{k} 0$, and the self-consolidation deformation of the foundation soil could be reset to zero, so that to calculate the displacement caused by the subsequent construction. According to the actual construction conditions, the construction of the pit can be constructed step by step.

Table 1 Selection of soil parameters

\begin{tabular}{|l|c|c|c|c|c|c|c|}
\hline Soil parameters & $\begin{array}{l}\text { Unsaturated } \\
\text { unit weight } \\
\gamma\left[\mathrm{KN} / \mathrm{m}^{3}\right]\end{array}$ & $\begin{array}{l}\text { Saturated } \\
\text { unit weight } \\
\gamma_{\mathrm{sat}}\left[\mathrm{KN} / \mathrm{m}^{3}\right]\end{array}$ & $\begin{array}{l}\text { Elastic } \\
\text { modulus } \\
\mathrm{E}\left[\mathrm{KN} / \mathrm{m}^{2}\right]\end{array}$ & $\begin{array}{l}\text { Poisson } \\
\text { ratio } v\end{array}$ & $\begin{array}{l}\text { Cohesive } \\
\mathrm{C} \\
{\left[\mathrm{KN} / \mathrm{m}^{2}\right]}\end{array}$ & $\begin{array}{l}\text { internal } \\
\text { friction } \\
\text { angle } \varphi\left[^{\circ}\right]\end{array}$ & $\begin{array}{l}\text { Dilation } \\
\text { angle } \\
\Psi\left[{ }^{\circ}\right]\end{array}$ \\
\hline Artificial fill (1) & 18 & 19 & 4520 & 0.4 & 15 & 12 & 0 \\
\hline Diluvial silty sand (3-1) & 19 & 20 & 4520 & 0.25 & 1 & 30 & 0 \\
\hline Diluvial medium sand (3-2) & 18 & 20 & 4520 & 0.23 & 1 & 34 & 4 \\
\hline Diluvial clay layer (4-1) & 12.8 & 14.5 & 1470 & 0.46 & 10 & 10 & 0 \\
\hline Mucky soil (4-2) & 17.7 & 18.2 & 3830 & 0.32 & 16.4 & 25.5 & 0 \\
\hline Granite residual soil and sandy clay (5H-1) & 17.8 & 18.7 & 3670 & 0.3 & 19 & 23.4 & 0 \\
\hline Hard plastic granite residual soil (5H-2) & 18.6 & 19.2 & 3850 & 0.25 & 19.6 & 24.6 & 0 \\
\hline Fully decomposed granite (6H) & 18.8 & 19.3 & 4210 & 0.22 & 40 & 30 & 0 \\
\hline Strongly decomposed granite (7H) & & & & & 0.32 \\
\hline
\end{tabular}

Table 2 Distribution of soil layers

\begin{tabular}{|c|c|c|c|c|c|c|c|c|c|c|c|c|c|c|c|}
\hline $\begin{array}{l}\text { Hole } \\
\text { NO. }\end{array}$ & $\begin{array}{l}\text { Soil } \\
\text { layer }\end{array}$ & $\begin{array}{l}\text { Top } \\
\text { level } \\
{[\mathrm{m}]}\end{array}$ & $\begin{array}{l}\text { Thick- } \\
\text { ness } \\
{[\mathrm{m}]}\end{array}$ & $\begin{array}{l}\text { Hole } \\
\text { NO. }\end{array}$ & $\begin{array}{l}\text { Soil } \\
\text { layer }\end{array}$ & $\begin{array}{l}\text { Top } \\
\text { level } \\
{[\mathrm{m}]}\end{array}$ & $\begin{array}{l}\text { Thick- } \\
\text { ness } \\
{[\mathrm{m}]}\end{array}$ & $\begin{array}{l}\text { Hole } \\
\text { NO. }\end{array}$ & $\begin{array}{l}\text { Soil } \\
\text { layer }\end{array}$ & $\begin{array}{l}\text { Top } \\
\text { level } \\
{[\mathrm{m}]}\end{array}$ & $\begin{array}{l}\text { Thick- } \\
\text { ness } \\
{[\mathrm{m}]}\end{array}$ & $\begin{array}{l}\text { Hole } \\
\text { NO. }\end{array}$ & $\begin{array}{l}\text { Soil } \\
\text { layer }\end{array}$ & $\begin{array}{l}\text { Top } \\
\text { level } \\
{[\mathrm{m}]}\end{array}$ & $\begin{array}{l}\text { Thick } \\
\text { ness } \\
{[\mathrm{m}]}\end{array}$ \\
\hline \multirow{6}{*}{$\begin{array}{l}\mathrm{Y} \\
\mathrm{T} \\
- \\
0 \\
5\end{array}$} & (1) & 28.10 & 1.8 & \multirow{6}{*}{$\begin{array}{l}\mathrm{Y} \\
\mathrm{T} \\
- \\
0 \\
3\end{array}$} & (1) & 28.29 & 0 & \multirow{6}{*}{$\begin{array}{l}\mathrm{Y} \\
\mathrm{T} \\
- \\
2 \\
0\end{array}$} & (1) & 27.33 & 2.8 & \multirow{6}{*}{$\begin{array}{l}\mathrm{Y} \\
\mathrm{T} \\
- \\
2 \\
1\end{array}$} & (1) & 27.1 & 10.7 \\
\hline & $(4-1)$ & 26.3 & 7.2 & & $(4-1)$ & 28.29 & 9.4 & & $(4-1)$ & 24.53 & 7 & & $(4-1)$ & 16.4 & 10 \\
\hline & $(5 \mathrm{H}-2)$ & 19.1 & 3 & & $(5 \mathrm{H}-2)$ & 18.89 & 10.9 & & $(5 \mathrm{H}-2)$ & 17.53 & 8.2 & & $(5 \mathrm{H}-2)$ & 6.4 & 5.5 \\
\hline & $(6 \mathrm{H})$ & 16.1 & 9.6 & & $(6 \mathrm{H})$ & 7.99 & 5.5 & & $(6 \mathrm{H})$ & 9.33 & 10.3 & & $(6 \mathrm{H})$ & 0.9 & 18.4 \\
\hline & $(7 \mathrm{H})$ & 6.5 & & & $(7 \mathrm{H})$ & 2.49 & & & $(7 \mathrm{H})$ & -0.97 & & & $(7 \mathrm{H})$ & -17.5 & \\
\hline & $\begin{array}{l}\text { Ground } \\
\text { water }\end{array}$ & 24.58 & & & $\begin{array}{l}\text { Ground } \\
\text { water }\end{array}$ & 25.19 & & & $\begin{array}{l}\text { Ground } \\
\text { water }\end{array}$ & 25.31 & & & $\begin{array}{l}\text { Ground } \\
\text { water }\end{array}$ & 24.3 & \\
\hline
\end{tabular}


Table 3 Characteristic parameters of waist (crown) beam and support

\begin{tabular}{|l|l|c|c|c|c|}
\hline $\begin{array}{l}\text { Section size } \\
{[\mathrm{m}]}\end{array}$ & $\begin{array}{l}\text { Unit weight } \\
{\left[\mathrm{KN} / \mathrm{m}^{3}\right]}\end{array}$ & $\begin{array}{l}\text { Cross sectional moment of } \\
\text { inertia } \mathrm{I}_{2}\left[\mathrm{~m}^{4}\right]\end{array}$ & $\begin{array}{l}\text { Cross sectional moment } \\
\text { of inertia } \mathrm{I}_{3}\left[\mathrm{~m}^{4}\right]\end{array}$ & $\begin{array}{l}\text { Poisson ratio } \\
\text { v }\end{array}$ & $\begin{array}{c}\text { Elastic modulus } \\
\mathrm{E}\left[\mathrm{KN} / \mathrm{m}^{3}\right]\end{array}$ \\
\hline Crown beam: $1.2 \times 1.0$ & 25 & 0.144 & 0.1 & 0.15 & $3 \times 10^{7}$ \\
\hline Waist beam: $0.8 \times 0.7$ & 25 & 0.030 & 0.023 & 0.15 & $3 \times 10^{7}$ \\
\hline Waist beam: $0.9 \times 0.8$ & 25 & 0.049 & 0.038 & 0.15 & $3 \times 10^{7}$ \\
\hline support: $1.0 \times 0.7$ & 25 & 0.058 & 0.029 & 0.15 & $3 \times 10^{7}$ \\
\hline support: $0.8 \times 0.7$ & 25 & 0.030 & 0.038 & 0.15 & $3 \times 10^{7}$ \\
\hline support: $0.9 \times 0.8$ & 25 & 0.049 & 0.013 & 0.3 & $3 \times 10^{7}$ \\
\hline Steel support: $\Phi 600, \mathrm{t}=14$ & 78 & 0.013 & & $2.1 \times 10^{8}$ \\
\hline
\end{tabular}

\section{Analysis of calculation results}

Spatial distribution of retaining structure displacement. The horizontal displacement of the diaphragm wall (enlarged 100 times) was shown in fig. 2. It shown that: Along the pit depth direction, the maximum horizontal displacement of retaining structure occurred near the bottom, that was caused mainly by that the earth pressure in the deep was larger than the shallow and the embedded depth of the diaphragm wall was relatively smaller. The horizontal deformation of foundation pit was all very small at the ends of Line 3 and Line 6, almost could be negligible. Along the length direction of Line 3 and Line 6, the foundation pit horizontal displacement was smaller at the external corner of the retaining structure, but it was relatively larger at the internal corner, the maximum displacement occurred at the intersection of two Lines. But the change rate of displacement was obviously different. Fig.2 (a) shown: From the point of external corner to the point of internal corner, the originally displacement increased rapidly, almost was in linearly. Then the growth rate slowed down gradually, finally tended to be invariant. It because the constraints of the supporting structure in the other direction were weakened gradually. The maximum displacement occurred at about 1/3-2/3 length of Line 6. Fig. 2 (b) showed the variation rules of lateral displacement along the length direction of Line 3 were similar with that of Line 6, but the maximum displacement was not in the middle of Line 3, but where the artificial digging piles lay, namely, at the lower retaining piles of two Lines intersection. Analyzed reasons: This may be because pile-wall depth and excavation depth of Line 3 was larger about $13 \mathrm{~m}$ than that of Line 6 , and the artificial digging piles that were constructed when the foundation pit were excavated to the bottom of Line 6 , was a relatively weak link of the retaining structure; on the other hand, they lay roughly in the middle of pit, the restriction came from the adjacent enclosure structure were weaker, so caused the lateral displacement to increase suddenly. Therefore, the monitoring of the parts of the lateral displacement should be strengthened in the construction process.

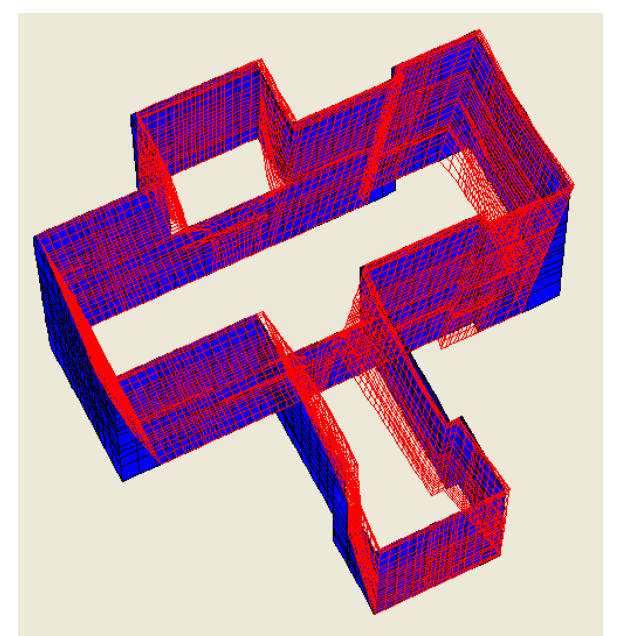

(a)horizontal displacement along Line 3

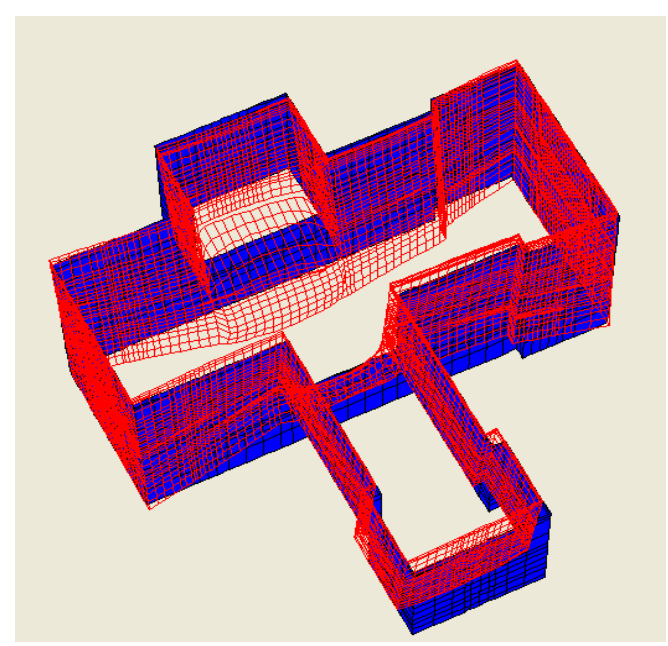

(b) horizontal displacement along Line 6

Fig.2 Three dimensional mesh deformation diagram of support structure 
Spatial distribution of ground surface settlement. Fig.3 was the spatial distribution of the ground surface settlement around foundation pit, it showed: The settlement occurred mainly near foundation pit, and decreased to zero gradually with increasing of the distance from the foundation pit. The most obvious settlement happened at the four ends of the foundation pit. In the way of the settlement influence region, Line 3 was obviously wider than Line 6 , Line 3 had an obvious influence range, about $1.2 \mathrm{H}_{3}$, but Line 6 was about $0.6 \mathrm{H}_{6}$ (here, $\mathrm{H}_{3}$ and $\mathrm{H}_{6}$ ware respectively the excavation depth of Line 3 and Line 6 ).

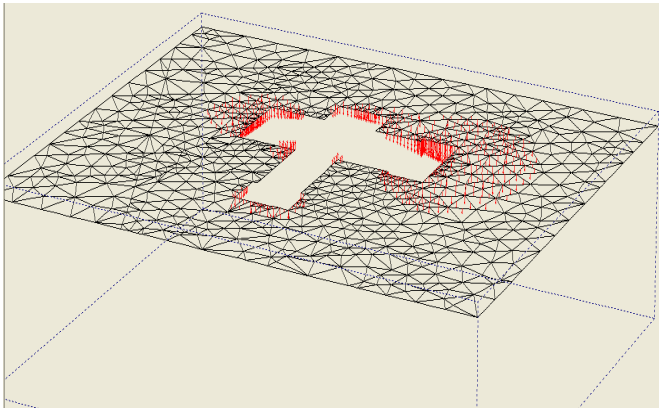

Fig.3 The spatial distribution of surface subsidence

Spatial distribution of the foundation pit bottom heave. Fig. 4 showed the spatial distribution of two Lines' foundation pit bottom heave. Because the excavation depth of Line 3 was larger than that of Line 6, so the foundation pit bottom heave of Line 3 was also more obvious than that of Line 6 on the whole. As for the spatial distribution of the bottom heave, was the middle bigger and the surround smaller. So the maximum heave deformation was at the center of the foundation pit, and should be controlled by reasonable construction organization.

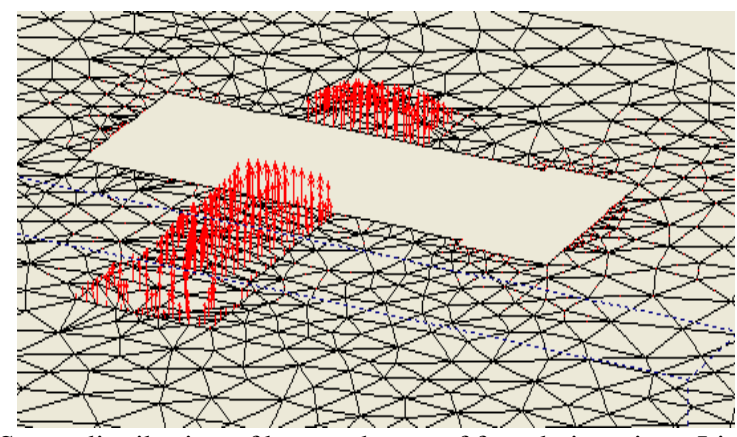

(a) Space distribution of bottom heave of foundation pit on Line

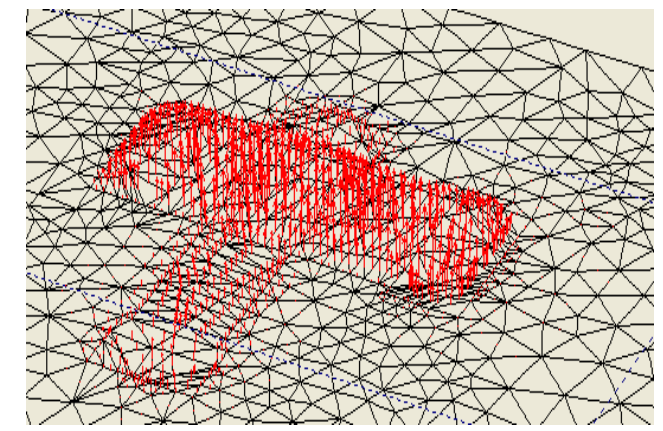

(b) Space distribution of bottom heave of foundation pit on Line 3

\section{Fig.4 The spatial distribution of foundation pit heave deformation}

Comparison of calculation results and monitoring results in the field. (1) Comparison of horizontal displacements. In order to prove the reliability of the calculation results, taken the measured inclined hole, J7 and T4 (Fig. 1), comparison the calculation values of foundation pit lateral deformation with the measured values were shown in Fig.5 and Fig.6. J7 lay in Line 3 and T4 lay in Line 6 . The contrast curves showed that the calculated values were slightly larger than the measured values, which may be related to that test soil samples were disturbed so that the indexes values of physical properties of test soil samples were slightly smaller, but the calculated and the measured were completely consistent in whole variation rule with pile depth.

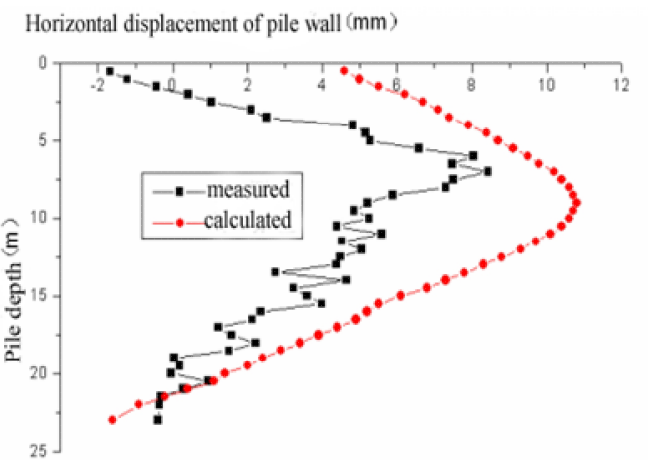

Fig.5 Comparison of calculated and measured values in horizontal displacement at $\mathbf{J 7}$

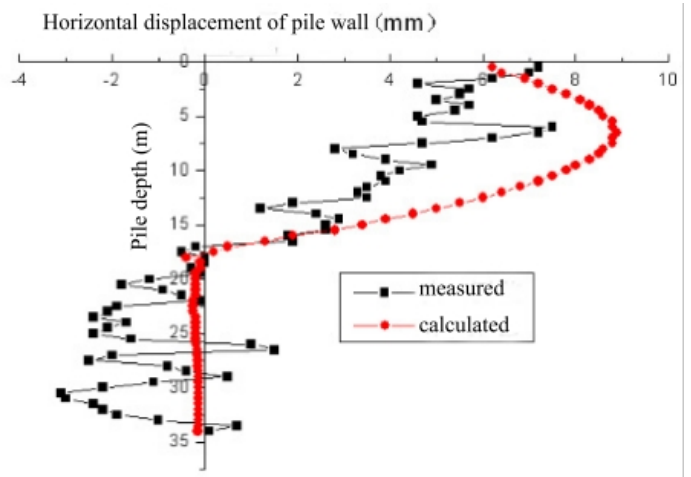

Fig.6 Comparison of calculated and measured values in horizontal displacement at $\mathrm{T4}$

(2) Comparison of support axial force. The distribution of First support's axial force measurement points were shown as Fig.1, the measurement points numbers were D0XX, the 
measured values and calculated values of axial force at measuring point were listed in Table 4, the table showed that the monitoring values and the calculated values were in good agreement, the support axial force of Line 3 were larger than that of Line 6. At D003 and D009 the axial force are the maximum, and they located just at the two metro Lines crossing, so we must strengthen the monitoring of the two supports' axial force, it is very important.

Table 4 Comparison of measured and calculated values of the first support axial force

\begin{tabular}{|l|c|c|c|c|c|}
\hline Measuring point & Measured value $[\mathrm{KN}]$ & Calculated value $[\mathrm{KN}]$ & Measuring point & Measured value[KN] & Calculated value[KN] \\
\hline D001 & 251 & 246 & D006 & 1395 & 1468 \\
\hline D002 & 2275 & 2101 & D007 & 1339 & 1586 \\
\hline D003 & 9069 & 10398 & D008 & 3255 & 3168 \\
\hline D004 & 1046 & 1052 & D009 & 6283 & 6314 \\
\hline D005 & 455 & 498 & D010 & 1972 & 1682 \\
\hline
\end{tabular}

\section{Conclusions}

According to the above calculation and analysis, we could draw the conclusions as followed:

(1) According to the spatial distribution of the foundation pit's deformation, it had spatial effect obviously, which could not be reflected by the two-dimensional plane model. Therefore, it had great practical significance to strengthen the three-dimensional simulation of foundation pit.

(2) The artificial digging piles that were constructed when the foundation pit were excavated to the bottom of Line 6, was a relatively weak link of the retaining structure; Therefore, the monitoring of the parts of the lateral displacement should be strengthened in the construction process.

(3) In the way of the settlement influence region, Line 3 was obviously wider than Line 6, Line 3 had an obvious influence range, about $1.2 \mathrm{H}_{3}$, but Line 6 was about $0.6 \mathrm{H}_{6}$

(4) As for the spatial distribution of the bottom heave, was the middle bigger and the surround smaller. So the maximum heave deformation was at the center of the foundation pit, and should be controlled by reasonable construction organization.

(5) Using the method to calculate foundation pit, the calculation results and monitoring results in site were in good agreement in the way of the lateral deformation and axial force, which proved that the calculation method of foundation pit was reliable.

\section{References}

[1] Chen Xiao-ping, Yan Jun. 3D pole system FEM analysis for bracing structure of deep foundation pit. Rock and Soil Mechanics,2001, 23 (3) : 258-261

[2] Xiong Chun-bao, Lei Li-gang, et. Internal force and deformation by 3D finite element analysis of support system of a typical deep excavation on soft soil. Rock and soil mechanics, 2006, 27 (s): 701-705

[3] Gao Wen-hua, Yang Lin-de. Three-dimension finite element analysis of deformation of the retaining structure of deep foundation pit in soft-clay[J]. engineering mechanics, 2000, (2):134-141

[4] Song Er-xiang, Lou Peng, Lu Xing-zheng, et. Nonlinear 3D finite element analysis of an extremely deep excavation support system[J].Rock and Soil Mechanics,2004,(4):538-543

[5] Zhao Hai-yan, Huang Jin-zhi. 3D Finite Element Analysis and Simulation of Deep

Excavations[J]. Journal of Shang Hai Jiao Tong university, 2001,(4): 610-613.

[6] Xu Zhong-hua. Deformation Behavior of Deep Excavations Supported by Permallent Structure in Shanghai Soft Deposit [D]. Shanghai jiaotong university, 2007:30-31.

[7] Zdravkovie L., PoRs D.M. and ST John H.D.. Modelling of a 3D excavation in finite element analysis. Geotechnique, 2005, 55(7): 497-513

[8] Ou C. Y, Chiou D.C. and Wu T.S.. Three-dimensional finite element analysis of deep excavations. Journal of Geotechnical Engineering, ASCE, 1996, 122(5): 337-345 